\title{
Fatos e memórias de uma paisagem ucraniana
}

\author{
Facts and memories of a ukrainian landscape
}

\author{
Solange Franciele Mageroski ${ }^{1}$ \\ Karla Rosário Brumes ${ }^{2}$
}

\begin{abstract}
Resumo
A paisagem de Prudentópolis-PR tomou características peculiares a partir da chegada de imigrantes ucranianos no final do século XIX e início do XX. Estes sujeitos têm contribuído para uma transformação dinâmica da paisagem local, e os atributos culturais impressos na paisagem fazem Prudentópolis ser conhecido como "a Ucrânia Brasileira". Neste sentido, o presente artigo exibe a paisagem por meio de notícias contidas em um Jornal. O Jornal Prácia, presente na comunidade ucraniana desde o ano de 1912, é um instrumento relevante para a compreensão desses sujeitos em seu novo território. Neste artigo, damos ênfase para a materialidade da cultura, ou seja, para os elementos visíveis na paisagem, visto que eles são muitos, materiais e imateriais.
\end{abstract}

Palavras-chave: Migração. Ucranianos. Paisagem.

\begin{abstract}
The landscape of Prudentópolis-PR got peculiar characteristics from the arrival of Ukrainian immigrants in the late nineteenth and early twentieth centuries. These individuals have contributed to a dynamic transformation of the local landscape, and the cultural attributes printed on the landscape make Prudentopolis be known as "the Brazilian Ukraine". Therefore, the present article exhibit the landscape, through news contained in a newspaper. The Prácia Newspaper present in the Ukrainian community since the year 1912 is a relevant instrument for the understanding of these individuals in their new territory. In this article, we emphasize the materiality of culture, in other words, the elements visible in the landscape, since there are many material and immaterial elements.
\end{abstract}

Keywords: Landscape. Culture. Ukrainians

\footnotetext{
1 Universidade Estadual do Centro Oeste-UNICENTRO, Guarapuava, Paraná, Brasil. solangefrancielem@gmail.com

2 Universidade Estadual do Centro Oeste-UNICENTRO, Guarapuava, Paraná, Brasil. kbrumes@hotmail.com

Artigo recebido em: 18/08/2018. Aceito para publicação em: 12/07/2019.
} 


\section{Introdução}

O município de Prudentópolis, no estado do Paraná, é conhecido como a "Ucrânia Brasileira" por acolher um grande número de imigrantes dessa etnia. A dinâmica migratória ocorrida nos anos finais do século XIX e no início do século XX produziu a configuração e transformação na paisagem do local. Seus códigos culturais impressos na paisagem permitem uma ampla visualização da cultura ucraniana no município. Tal condição pode ser observada por meio das cores dos bordados, das pinturas coloridas em residências; nos sabores das comidas típicas; nos sons de música ucraniana em festas e rádios locais; na arquitetura de casas e igrejas, entre outros elementos.

Nesse sentido, a fim de compreender como ocorre esse processo, o presente artigo faz uma breve discussão sobre o conceito de paisagem, pois dá suporte para o desenvolvimento do objetivo proposto, que é a análise da paisagem material cultural em Prudentópolis. Após, apresentamos a constituição da paisagem em si por meio dos impressos do Jornal Prácia, um impresso centenário presente na comunidade ucraniana da cidade desde 1912. Não discutimos a paisagem apenas a partir daquilo que pode ser observado in loco, mas através das considerações e apontamentos que advêm da busca dos elementos constitutivos da paisagem de Prudentópolis a partir da inserção dos ucranianos nos registros impressos do Jornal Prácia.

Utilizamos esse objeto porque dá acesso às leituras da história, das práticas culturais e das experiências de vida dos imigrantes ucranianos e seus descendentes ao longo do tempo. Isto nos permite compreender como esses sujeitos, a partir das suas particularidades, são parte fundamental na formação da paisagem de Prudentópolis. 


\section{Conceituação de paisagem}

Iniciamos esta interlocução a partir da apresentação do conceito de paisagem dentro da perspectiva da cultural. Em outras palavras, partimos do conceito de paisagem como forma de descrição e de expressão do material e do imaterial em Prudentópolis iniciando com a chegada de imigrantes ucranianos.

Os símbolos dispostos na paisagem fazem a mediação entre a imaginação e o real. Os significados atribuídos a esses símbolos levam-nos a uma dimensão imaginativa, onde desempenham um papel importante, uma vez que sua união com a imaginação de um indivíduo justifica as interpretações variadas atribuídas às paisagens. A carga cultural e a construção identitária de cada um ésão processos que ocorrem ao longo do tempo e com diferentes experiências de espacialidade.

A paisagem, como um dos conceitos-chave da ciência geográfica, ao longo do tempo, aderiu a múltiplas interpretações, proporcionando um vasto campo de estudo entre elementos da natureza e da sociedade. Depende sempre de seu contexto cultural e histórico, isto é, da relação entre uma série de pontos de vista que, às vezes, podem ser contraditórios, mas convergem para o que pode ser reconhecido singularmente como um processo cultural.

Para Corrêa (2011, p. 10), "a paisagem, contudo, não é apenas forma material resultante da ação humana transformando a natureza. É também forma simbólica impregnada de valores [...]". Este autor aponta que os valores dão o sentido atribuído à paisagem, desconstruindo a ideia da paisagem como tudo o que é visível e construindo de conjunto e justaposição de significados, assim como todas as ações humanas.

A compreensão da paisagem, enquanto forma simbólica, advém dos estudos promovidos pelo movimento da nova geografia cultural dos anos de 1970, com destaque para aqueles apresentados por Denis Cosgrove (1979; 
$1983 ; 1993 ; 1995 ; 1998)$, que apresenta a Geografia histórico-cultural da paisagem associada às transformações econômicas, técnicas, artísticas, sociais ou políticas.

Considera a paisagem como síntese pictórica externa, que representa estaticamente as relações entre vida humana e natureza, constituindo-se em "poderoso meio através do qual sentimentos, ideias e valores são expressos" (COSGROVE, 1993, p. 8) e, simultaneamente, "modela esses mesmos sentimentos, ideias e valores" (CORRÊEA, 2011, p. 12).

No caso dos ucranianos, ao se fixaram no espaço urbano, mesmo que em menor número, se comparados com aqueles que se fixaram no espaço rural, incorporam inúmeros aspectos à paisagem de Prudentópolis a partir de sua origem. . Neste sentido, ela veio sendo transformada pelos imigrantes de acordo com seu próprio jeito de ser, considerando seus costumes, crenças e ensinamentos. Isto foi manifestado na paisagem por meio das construções, como teatro, comércio, escola, clube e igreja, além das manifestações culturais tanto no espaço urbano como no rural.

Segundo Hirsch (1995, p. 23), a paisagem é um processo que se desenrola entre o "lugar e o espaço, o dentro e o fora, a imagem e a representação”.

$\mathrm{O}$ conceito de início liga-se à

[...] abordagem neopositivista [que] direcionou para o termo região tentando dar enfoque ao processo de abstração da realidade física, conforme a sua metodologia quantitativa. A abordagem marxista (materialista), pouco interessada na geograficidade da paisagem, identificou-se com o termo região, o qual define como um produto territorial da ação entre capital e trabalho. As abordagens da ecologia humana, entretanto, beneficiam - se da ideia da paisagem ao demonstrar suas características sistêmicas, reunindo diversas categorias no mesmo recorte espacial (SCHIER, 2003, p. 80).

A partir da década de 1970, destacam-se discussões sobre paisagem cultural, principalmente aquelas que trazem análise de imagens, conteúdo simbólico, vínculos de grupos humanos com o espaço, análise de 
representações e assim por diante, contemplando aspectos de uma determinada cultura no espaço. Trazemos alguns autores, suas definições e abordagens em relação ao conceito de paisagem mais ligados às questões culturais.

A paisagem deve ser entendida como um texto em que cada um que a lê pode significá-la de forma diferente, de acordo com suas lentes culturais, suas experiências e vivências. Ela também é resultado da ação de uma sociedade que, ao longo do tempo, expressa suas marcas culturais sobre a paisagem natural.

Segundo Melo (2001, p. 30), "no início do século XX, a paisagem foi um dos primeiros temas a ser abordado numa perspectiva cultural pelos geógrafos alemães". Já Corrêa (1995, p. 4) afirma que se trata “[...] de um conjunto de formas materiais articuladas entre si no espaço como os campos, as cercas vivas, os caminhos, as casas, a igreja, entre outras, com seus estilos e cores, resultante da ação transformadora do homem sobre a natureza".

Santos (1988, p. 23) apresenta uma discussão sobre paisagem e produção dos instrumentos de trabalho, onde estes últimos se interligam ao processo de produção. Para o autor, "a paisagem não se cria de uma vez, mas por acréscimos, substituições [...] uma paisagem é uma escrita sobre a outra, é um conjunto de objetos que têm idades diferentes, é uma herança de muitos momentos" (SANTOS, 1988, p. 23).

Ainda para Santos (2002), a paisagem é coexistência de formas criadas em determinados momentos históricos e atualmente. A paisagem pode ser pensada sob duas formas: marca e matriz. Como marca pode ser compreendida a partir das ações humanas, sendo percebida, experienciada e valorizada. Como matriz, contempla e exprime as características culturais de uma determinada sociedade, tornando-se a base, a inspiração e o reflexo dos anseios de um povo. 
É preciso compreender a paisagem de dois modos: por um lado ela é vista por um olhar, apreendida por uma consciência, valorizada por uma experiência, julgada (e eventualmente reproduzida) por uma estética e moral, gerada por uma política, etc. e, por outro lado, ela é matriz, ou seja, determinada em contrapartida, esse olhar, essa consciência, essa experiência, essa estética e essa moral, essa política etc. (BERQUE, 1998, p. 86).

Neste sentido, é perceptível a complexidade do conceito provido da Geografia ligado à cultura, e encaminha nosso estudo por um viés cultural, simbólico e material, sabendo que o imaterial também é perceptível quando falamos de uma paisagem a partir de uma cultura. Então, apresentamos a materialidade da cultura ucraniana em Prudentópolis.

De acordo com Caetano e Bezzi (2011, p. 458), "a materialidade e a imaterialidade da paisagem têm importância nas pesquisas direcionadas ao olhar crítico da Geografia”, capaz de expressar as marcas e ações humanas sobre um determinado espaço. Explicam-se por esta via as construções, superstições, crenças, religiosidade, dentre outras que imprimem marcas na paisagem, sejam elas materiais ou imateriais.

Pode-se afirmar, então, que a paisagem é construída a partir dos indivíduos de uma determinada cultura, que atribuem elementos ao lugar, sejam eles presentes na materialidade ou imaterialidade, de acordo com os costumes, tradições, atividades cotidianas, etc. Ainda de acordo com Caetano e Bezzi (2011, p. 260),

a representatividade da paisagem cultural não se refere, apenas, aos aspectos materializados, mas a tudo que faz parte dela, sejam os aromas, sons, as pessoas, animais e objetos que "preenchem" essa paisagem de vida, cores e peculiaridades.

A paisagem é um conceito de síntese construído a partir da compreensão do lugar. Assim, "muito mais que uma justaposição de detalhes pitorescos, a paisagem é um conjunto, uma convergência, um momento vivido, uma ligação interna, uma ‘impressão’ que une todos os elementos” (DARDEL, 2011, p. 41). 
Deve ser encarada não apenas como um objeto de estudo, refletido e interpretado intelectualmente, mas como uma forma de vivência na sua plena positividade do cotidiano das pessoas. Conforme coloca Dardel (1990, p. 54), "a paisagem não se refere à essência, ao que é visto, mas representa a inserção do homem no mundo, a manifestação de seu ser para com os outros, base de seu ser social".

A paisagem em Prudentópolis é constituída, nessa perspectiva, pelos códigos da cultura ucraniana. Os imigrantes mantinham consigo memórias de acontecimentos, festividades, da religiosidade fundamentada em sua vida no país de origem. Logo, eles reproduziram e ainda reproduzem aquilo que trouxeram consigo, atribuindo significados dessa cultura no espaço inserido.

\section{O uso do Jornal Prácia como fonte histórica na compreensão da paisagem}

O uso de jornais como fonte bibliográfica possibilita, ao pesquisador, compreender aspectos da sociedade atual e também lidar com o passado histórico. Assim, a paisagem objeto de nosso estudo pode ser observada nas tiragens do jornal pesquisado, por meio de diferentes elementos materiais e imateriais. O Jornal Prácia foi usado como fonte de pesquisa por autores como Polak (2010), Lupespa (2013), Szeremeta (2015) and Prado (2017).

A fim de encontrar os elementos que foram conformando a paisagem de Prudentópolis ao longo do tempo, expressos no Jornal a partir da chegada dos imigrantes ucranianos, exploramos o conteúdo de todas as edições entre os anos de 1912-2000. Isto porque não era possível escolher aleatoriamente uma ou outra edição sem conhecer seu conteúdo. Então, escolhemos as unidades, fizemos o tratamento dos dados e traduzimos as informações contidas no Jornal que faziam referência aos aspectos materiais e imateriais expressos na paisagem. Ressalta-se o fato de que o Jornal foi publicado 
exclusivamente na língua ucraniana até 1995. Desde então os artigos são bilíngues, em ucraniano e português.

Ao definirmos o uso de um impresso como fonte de pesquisa, seguimos a ideia que eles são a reconstrução da realidade, e não apenas um espelho, pois a notícia não implica no fato em si, mas em uma abordagem, em um relato daquilo que ocorreu. No caso do Jornal Prácia, por mais que exista uma limitação simbólica, por ser ele editado por um seguimento religioso, isto não significa que o que vem sendo relatado ao longo do tempo não seja verdade. A partir de concepções subjetivas expressas no Jornal, selecionamos os aspectos da realidade que nos interessavam, a fim de compreender relações expressas na paisagem.

Prácia significa "trabalho" em ucraniano, e começou a circular em Prudentópolis em novembro de 1912. Nos primeiros anos, o Jornal foi editado em uma tipografia instalada na construção aos fundos do mosteiro dos padres basilianos, onde permaneceu até o ano de 1952. Depois, edificouse um prédio próprio para redação e impressão, permanecendo até os dias atuais com o nome de Gráfica Prudentópolis.

Segundo Escudero (2007), os jornais “imigrantes" possuíam diversos objetivos, cada qual de acordo com as necessidades da comunidade imigrante. As publicações dedicavam-se “à identificação social, à busca pela informação, à quebra do isolamento e ao contato com a sociedade de adoção, à sobrevivência na nova terra e à preservação e manutenção de culturas próprias" (ESCUDERO, 2007, p. 82).

O nº 24 de 2012 do Jornal Prácia, de característica comemorativa, fez referência à sua primeira edição do Jornal editada no Brasil, e trazia a seguinte nota de apresentação do editor aos imigrantes:

Os padres basilianos, já faz dois anos, vêm publicando o "Missionário Ucraniano no Brasil" abordando temas estritamente religiosos. Mas havia necessidade de oferecer ao povo informações de caráter cultural e político, e com este propósito nasce o Prácia, que vai publicar notícias e comentários sobre temas políticos, 
culturais e também religiosos, indo, assim, ao encontro da necessidade do povo ucraniano no Brasil, com a intenção de elevar o nível cultural, informar sobre acontecimentos mundiais, ucranianos e brasileiros. E como é impossível compreender um trabalho formativo do cristão sem a fé e sem a religião, [...] já faz mais de um ano que entre os rutenos paranaenses reinava um clima de incerteza, pois, ainda que se sentisse a falta de um periódico educativo, era difícil contornar a situação. Publicando este primeiro número desejamos, com isso, ir ao encontro das necessidades espirituais do nosso povo ruteno no Brasil, elevar seu nível de instrução, construir nele a consciência nacional e unir todas as nossas forças de trabalho educacional do povo (PRÁCIA, 2012, nº 24, p. 9).

Apesar de ser um jornal editado pela igreja ucraniana local e, por esta razão, trazer informações relacionadas à religiosidade, seu conteúdo também trazia informações outras, como as notícias sobre o naufrágio do Titanic em 1912, sobre a Fome na Ucrânia (1932-1933), e sobre a imigração ucraniana no final do século XIX e início do século XX.

Sobre as mudanças que foram incorporadas ao veículo de comunicação ao longo do tempo, a notícia publicada na edição de $\mathrm{n}^{\circ} 24$ de 2012 versava sobre as mudanças de estilo das letras e o início do uso das máquinas elétricas (Figura 1).

[...] em 1940 passou-se a usar a eletricidade para a impressão e a datilografia no Intertype, e mais tarde, o Lynotype para a composição das letras, e somente em 1996 a tipografia passou a executar trabalhos gráficos e a impressão entrou na era da computação e uso de fotolitos. Já a primeira máquina elétrica foi adquirida em 1938 (PRÁCIA, 2012, nº 24, p. 9-10).

Outra mudança de detaque anunciada ainda na edição n ${ }^{\circ} 24$ de 2012 dava conta que o Jornal, publicado quinzenalmente desde sua primeira edição, passou a semanal, em vistude da modernização dos equipamentos. 
Figura 1 - Primeira máquina impressora elétrica do Jornal Prácia, 1938

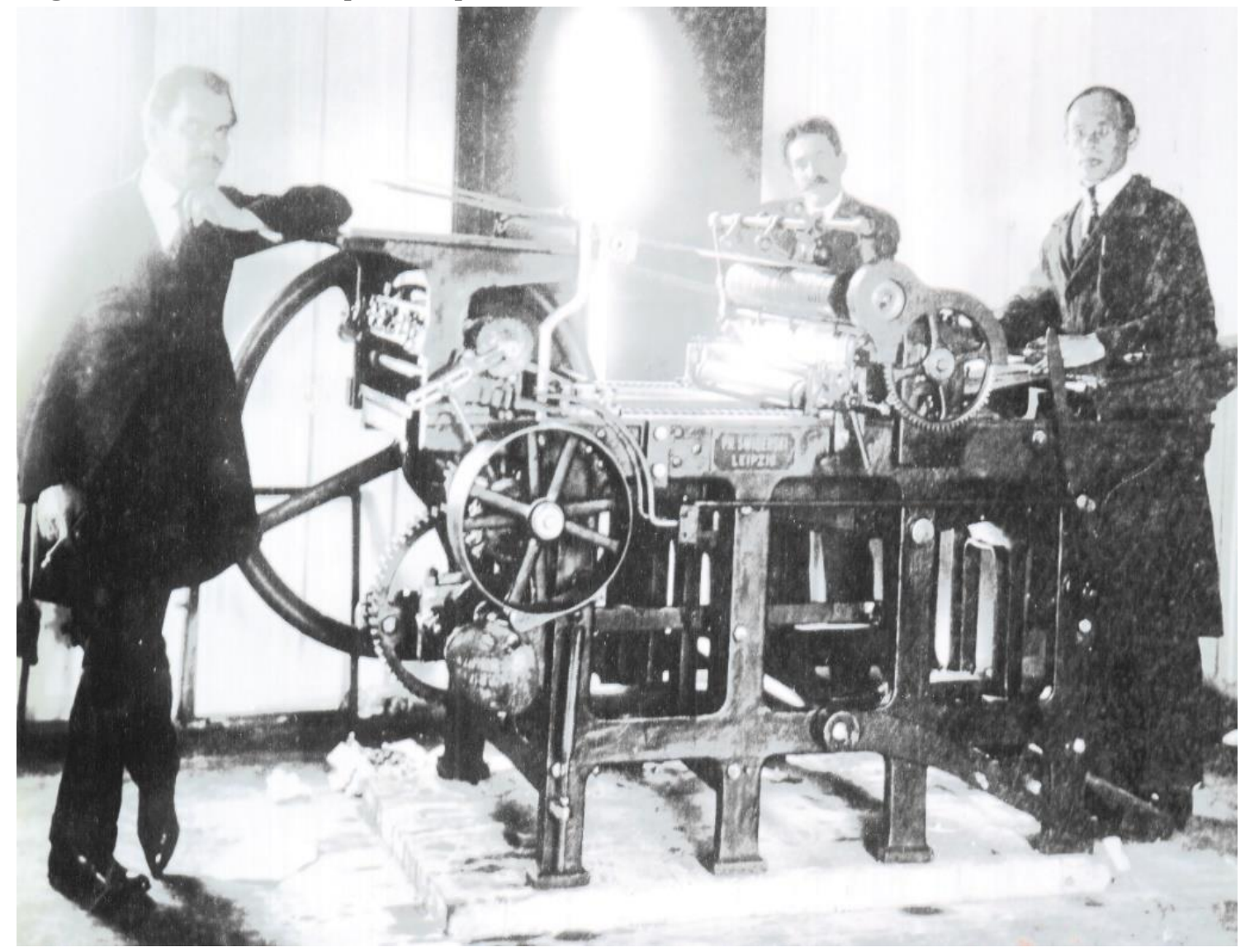

Fonte: Acervo Museu do Milênio, Prudentópolis - PR, 1938.

O objetivo era a leitura do Jornal por parte não só dos imigrantes que tinham domínio do idioma, também dos decendente já nascidos no Brasil. Assim, inicialmente foi publicado exclusivamente na língua ucraniana, e a partir de 1995 passou a ser bilíngue. Essa informação também fez parte do Jornal em 2012: "vocês sabiam que nosso Jornal começou a introduzir o português, a partir da publicação do folheto Rumo Jovem em 1995 se tornando totalmente bilingue em 1998?" (PRÁCIA, 2012, n 24, p. 10). Esta mudança ocorreu devido a muitos leitores não conseguirem mais acompanhar as leituras em ucraniano.

A tradução do periódico também pode ser considerada inovadora. A Lei $\mathrm{n}^{\circ} 10.406$, de 10 de janeiro de 2002, pontua que "todos os documentos redigidos em língua estrangeira serão traduzidos para o português para ter 
efeitos legais no país" (BRASIL, 2002), mas o jornal tornou-se bilíngue sete anos antes. Outro ponto a ser levado em consideração é que, no início das publicações, o número de leitores era reduzido. Entretanto, o perfil variou ao longo dos anos (Quadro 1). O número de leitores elevou-se entre os anos de 1924 e 1937, justificado pela vinda de uma nova leva de imigrantes ucranianos para o Brasil. Também a partir do quadro 1 é possível verificar que a circulação do periódico abrange comunidades ucranianas no Brasil e em outros países, como Argentina, Estados Unidos, Canadá, Itália, Ucrânia, Inglaterra, Alemanha e França. As atividades do Jornal ainda se mantém nos dias de hoje. Contudo, o número de leitores é menor que outrora, e a maioria dos assinantes está nos estados do Paraná, Santa Catarina e São Paulo (Quadro 1).

Quadro 1 - Variação e origem dos assinates do Jornal Prácia entre 1912-2012.

\begin{tabular}{|c|c|c|}
\hline ANO & ASSINANTES & ORIGEM \\
\hline $1912-1923$ & 800 & $\begin{array}{l}\text { Brasil: } 800 \\
\text { Exterior: -..- }\end{array}$ \\
\hline 1923 & 987 & $\begin{array}{c}\text { Brasil: } 935 \\
\text { Exterior: } 52\end{array}$ \\
\hline 1924 & 1700 & $\begin{array}{l}\text { Brasil: } 1700 \\
\text { Exterior: -.-- }\end{array}$ \\
\hline 1937 & 2500 & $\begin{array}{l}\text { Brasil: } 2500 \\
\text { Exterior: ---- }\end{array}$ \\
\hline 2012 & $\begin{array}{c}\text { Brasil: } 1092 \\
\text { Outros países: } 47\end{array}$ & $\begin{array}{c}\text { Brasil: } \\
\text { Estado do Paraná: } 935 \\
\text { Estado de Santa Catarina: } 95 \\
\text { Estado de São Paulo: } 36 \\
\text { Outros Estados: } 26 \\
\\
\text { Outros países: } \\
\text { Argentina: } 5 \\
\text { USA: } 8 \\
\text { Canadá: } 5 \\
\text { Itália: } 9 \\
\text { Ucrânia: } 8 \\
\text { Inglaterra: } 4 \\
\text { Alemanha: } 7 \\
\text { França 1 }\end{array}$ \\
\hline
\end{tabular}

Fonte: Jornal Prácia, no 24, p. 11, 1 de mar. de 2012.

Org: Mageroski (2017). 
Até o ano de 2012 havia 6410 números do periódico publicados. Todavia, vale ressaltar que o Jornal deixou de ser publicado entre os anos de 1941 a 1946, período conhecido pela campanha de nacionalização de Getúlio Vargas, por meio do Decreto-Lei $\mathrm{n}^{0}$ 1. 545, de 25 de agosto de 1939, que "previa a adaptação do imigrante ao território brasileiro, proibia a língua, e a publicação de revistas, jornais, folhetos em língua estrangeira" (BRASIL, 1939).

Desde o primeiro periódico, o Jornal desempenhou papel importante para a manutenção da cultura entre os ucranianos. As publicações orientavam os imigrantes a respeito de como deviam exercer suas práticas culturais e religiosas, bem como aproximavam esses sujeitos com suas raízes. Uma vez que noticiava os fatos acontecidos na Ucrânia, proporcionava contato do imigrante com suas origens. Dentro desta perspectiva, o Jornal aparece como principal meio de compreensão dos ucranianos em Prudentópolis. Assim, pode ser utilizado como pesquisa em diversos campos, pois os textos transitam na comunidade há mais de um século, orientando, transmitindo valores e informações aos imigrantes e, atualmente, aos descendentes.

\section{Prudentópolis e a imigração ucraniana}

O município de Prudentópolis, constituído em 1907, após se emancipar de Guarapuava, tem esse nome em homenagem ao ex-presidente do Brasil entre 1894 e 1898, Prudente de Morais, dista 200 quilômetros da capital Curitiba, e possui 52.125 habitantes (IBGE, 2017).

Enquanto os ucranianos vivenciavam condições severas sob o domínio austro-húngaro (1891-1914), em território brasileiro, circunstâncias como o fim do regime escravocrata, em 1888, modificavam as relações sociais e do trabalho. $\mathrm{O}$ governo incentivava a entrada de europeus no país para suprir as grandes lacunas produtivas na agricultura. 
Segundo Lopez (1983, p. 12), “o império resistiu sempre a uma abolição brusca, com medo de abalar os fundamentos da propriedade”. Quando o fim do regime foi instaurado, não houve alternativa, a não ser importação de mão de obra imigrante. Além do mais, tinha-se grande preocupação em ocupar vazios demográficos. Desta maneira, "governos das jovens nações americanas procuram resolver o problema da ocupação efetiva do solo, necessária à soberania nacional e à sua valorização econômica" (BALHANA, 1996, p. 41).

A assinatura da Carta Régia foi uma decisão fundamental para o governo brasileiro promover propagandas massivas nos países europeus, prometendo melhores oportunidades e riquezas no continente americano para o imigrante, muitas vezes alimentando ilusões. "O país da Cocanha do século XVI metamorfoseou-se, no século XIX, em paraíso das delícias e impulsionou milhares de europeus a transferirem-se para a América, realizando o movimento conhecido como a Grande Migração" (ANDREAZZA, 1996, p. 14).

A imigração ucraniana para Prudentópolis ocorreu em três períodos. O primeiro, entre 1895 e 1897, foi reflexo da superpopulação rural, do atraso na industrialização e das más condições socioeconômicas enfrentadas pela Ucrânia. O segundo, de 1908 a 1914, teve por motivação o pós Primeira Guerra Mundial. O terceiro, entre 1947 e 1951, teve como principal fator de impulsão a Segunda Guerra Mundial (BURKO, 1963; BORUSZENKO, 1995; GUÉRIOS, 2007).

Os imigrantes já em território brasileiro eram direcionados para diversos Estados, majoritariamente para o Paraná e Santa Catarina. Também, grupos menores estabeleceram-se no Estado de São Paulo, Rio Grande do Sul, Minas Gerais, Goiás e Rio de Janeiro (BURKO, 1963).

O grande fluxo migratório de ucranianos, do fim do século XIX até a década de 1951, no século XX, formalizou a pequena vilinha de Firmo Mendes, um núcleo receptor de imigrantes. De acordo com Guérios (2007), a 
vinda massiva de imigrantes fez o governo federal abrir novos núcleos coloniais, "a pedido da União para localizar de modo imediato grande número de polacos" (RELATÓRIO, 1907, 61 apud GUÉRIOS, 2007, p. 116). Prudentópolis foi, então, uma das colônias fundadas para receber imigrantes.

\section{Elementos constitutivos de uma paisagem ucraniana expressos no Jornal} Prácia

A abordagem do espaço vivido valoriza a memória das pessoas a respeito da sabedoria, das culturas e das relações sociais de produção, elaboradas e transformadas em identidades, que se fixam no lugar, como expressão particular de modos de vida. A noção de espaço assume o significado de espaço vivido, considerando os sentimentos e as ideias de um grupo ou povo sobre o espaço das experiências.

Segundo Pereira (2013), a produção e construção da paisagem humana do espaço geográfico vão obedecer aos desejos, sonhos, emoções e razões dos cidadãos que participam dela. Neste sentido, a paisagem de Prudentópolis é permeada de elementos culturais do país de origem dos imigrantes ucranianos. Segundo Cosgrove (1995, p. 42), "a paisagem é intimamente ligada à cultura e à ideia de que as formas visíveis são representações de discursos e pensamentos. Assim, a paisagem aparece como um lugar simbólico".

Neste contexto, Saquet (2007, p. 145) afirma que

O homem cria, com o desejo, com a vontade de construir uma paisagem ideal, na qual possa reconhecer a sua história sua cultura. O desejo cria imagens, que são instrumentos de estudo e para construir novos territórios. A paisagem significa estas imagens do real ou do próprio imaginário (científico e/ou artístico), o que revela, simultaneamente, uma forma de ligação da paisagem com o território, como abstração e representação no desejo por novas paisagens e na projeção do futuro (SAQUET, 2007, p. 145). 
No Jornal Prácia, sobretudo nas edições que faziam referência aos primeiros períodos migratórios, observamos a descrição de uma paisagem que salienta os aspectos ligados à religião. Por este motivo, notícias referentes à construção da capela pelos imigrantes ucranianos eram bem comuns. No Jornal encontramos o trecho de uma carta escrita por um sacerdote vindo da Ucrânia para prestar auxílio aos imigrantes no ano de 1897, e que fazia referência à construção:

[...] Com a ajuda de Deus eu já construí para o nosso povo uma espaçosa capela com duas sacristias, presbitério e coro. Ela tem a capacidade para 700 pessoas. A capela está dedicada a São Basílio Magno e as primeiras celebrações vou realizar no dia dos Três Santos Patriarcas, em 30 de janeiro. Porém, não tenho nenhuma ícone [...] (PRÁCIA, 1995, n 15, p. 8 apud MISSIONAR JOVKA, 1898, p. 174-176).

Nesse trecho da carta publicada, identificamos a "ordem" de como a igreja no Brasil fosse construída, o que permitiria que os migrantes tivessem um elemento material edificado a partir das lembranças dos elementos da paisagem sob a qual viviam na Ucrânia.

O número 48 do Jornal Prácia de 1923 trouxe a notícia de que a maior igreja ucraniana do Brasil iria ser construída "[...] no lugar mais nobre do município [...] (PRÁCIA, 1923, nº 48, p. 13). A igreja teria de ser constuída com as mesmas características daquelas presentes no país de origem: estilo bizantino, rito litúrgico bizantino, idioma, entre outros.

A Igreja Matriz de São Josafat teve sua construção finalizada no decorrer da década de 1930. Todavia, na medida em que a igreja ia sendo erguida, as publicações iam noticiando os detalhes/etapas: a "[...] bênção da pedra fundamental da igreja" (PRÁCIA, 1923, nº 46, p. 3); "a inauguração da pedra debaixo do altar' (PRÁCIA, 1929, n 12, p. 2); "os festejos realizados para apetrechos para a igreja, como a instalação de lustres" (PRÁCIA, 1935, ${ }^{\circ}$ 
48, p. 2); e "a pintura da igreja” (PRÁCIA, 1936, n 44, p. 2). A consagração da igreja já estabelecida, que ocorreu em 1939:

[...] No domingo, dia 27 de agosto de 1939, Vossa Excelência, o Visitador Apostólico Dom Ivan Buczko, solenemente realizou a consagração da nova igreja em Prudentópolis. A emocionante cerimônia da consagração começou às 8 horas da manhã com a procissão conduzindo Sua Excelência, o bispo, do mosteiro para a igreja [...] (PRÁCIA, 1939, $\mathrm{n}^{\circ} 34$, p. 4).

As descrições da construção no Jornal, o significado e as funções da igreja são os elementos constitutivos da paisagem de um lugar, os chamados elementos materiais e imateriais. Os primeiros podem ser vistos nas formas arquitetônicas da igreja; e os segundos referem-se ao rito, às celebrações em língua ucraniana.

$\mathrm{Na}$ paisagem do novo lugar de moradia dos ucranianos começavam a ser inseridos elementos que marcariam, até os dias atuais, a presença desse grupo (Figura 2).

Segundo Pereira e Soares (2012), a paisagem está impregnada dos próprios elementos da natureza, da cultura do seu povo. O Jornal trouxe informações sobre a construção da igreja, ao passo que retratou a configuração de uma paisagem que começou a se conformar, também, a partir da presença de imigrantes ucranianos. De acordo com Vendruscolo (2009, p. 196), “a arquitetura preservada representa a cultura e a história materializada em monumentos e construções que tomam sentido e mantém vivos os significados da memória coletiva”. Os laços culturais entre os ucranianos no Brasil, bem como o sentimento de "ucraino-brasilidade" são recorrentes ao passado e aos valores históricos do grupo. Costa (2008, p. 1) salienta que "estas relações são mediatizadas pelos símbolos que podem ser uma realidade material e que une-se a uma ideia, um valor, um sentimento". 
Figura 2 - Igreja Matriz de São Josafat, Prudentópolis- PR, 2017

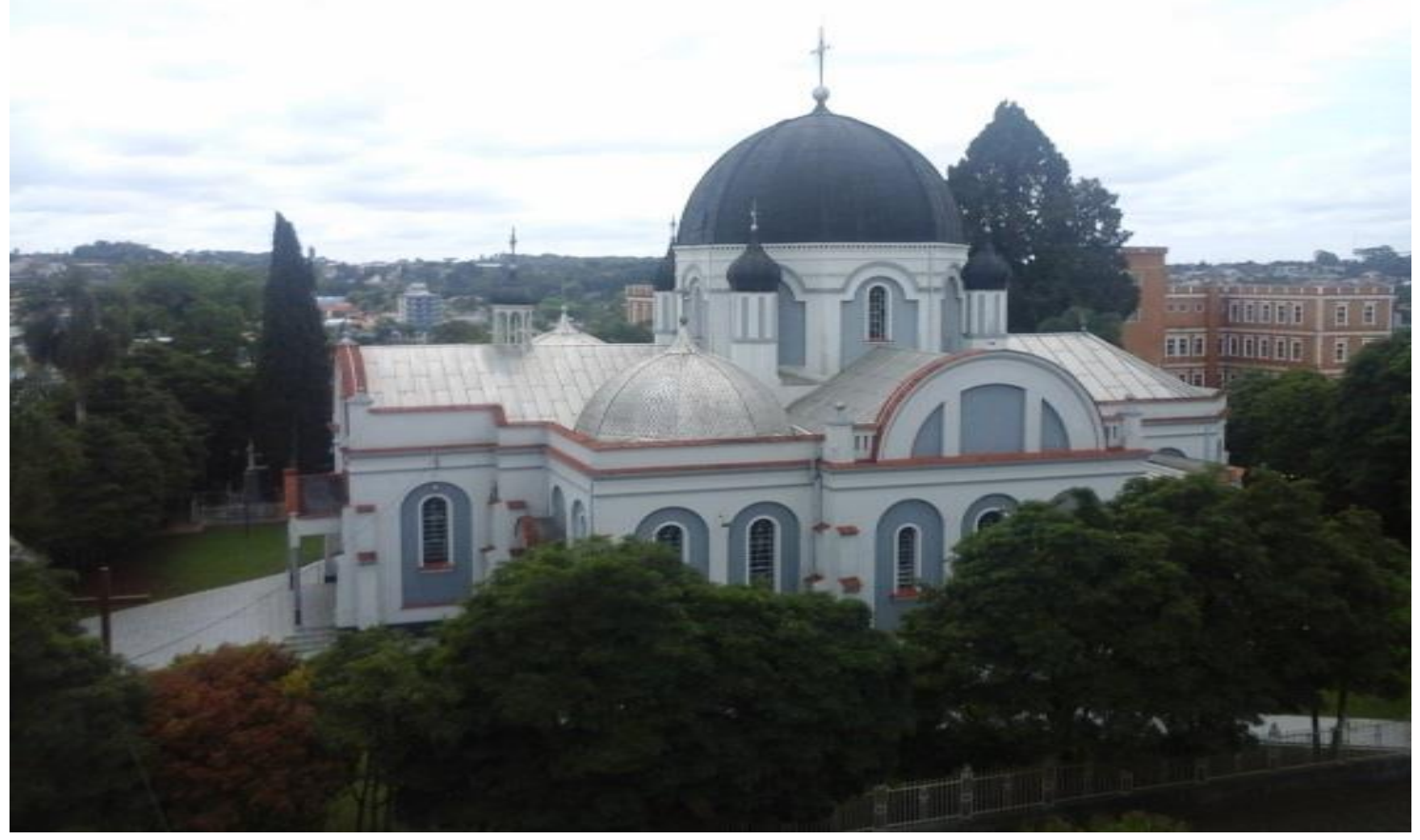

Fonte: Mageroski (2017).

Outro elemento cultural material perceptível na paisagem de Prudentópolis é o memorial em homenagem ao poeta ucraniano Taras Chevtchenko, construído em 1985 (Figura 3).

O Jornal trouxe várias matérias a respeito da construção, visando sempre a informar a comunidade ucraniana: “[...] lançamento da pedra angular do monumento da Praça Taras Chevtchenko, no dia 12 de agosto de 1986 [...]” (PRÁCIA, 1986, n 16, p. 5); promoções da igreja São Josafat em prol da construção: “[...] Convite! Prudentópolis e região. No dia 17 de maio, nesta cidade, terá uma festa em benefício da construção do monumento Taras Chevtchenko em comemoração a 1000 anos do cristianismo na Ucrânia [...]" (PRÁCIA, 1988, nº 18, p. 15). 
Figura 3 - Memorial Taras Chevtchenko, Prudentópolis-PR, 2017

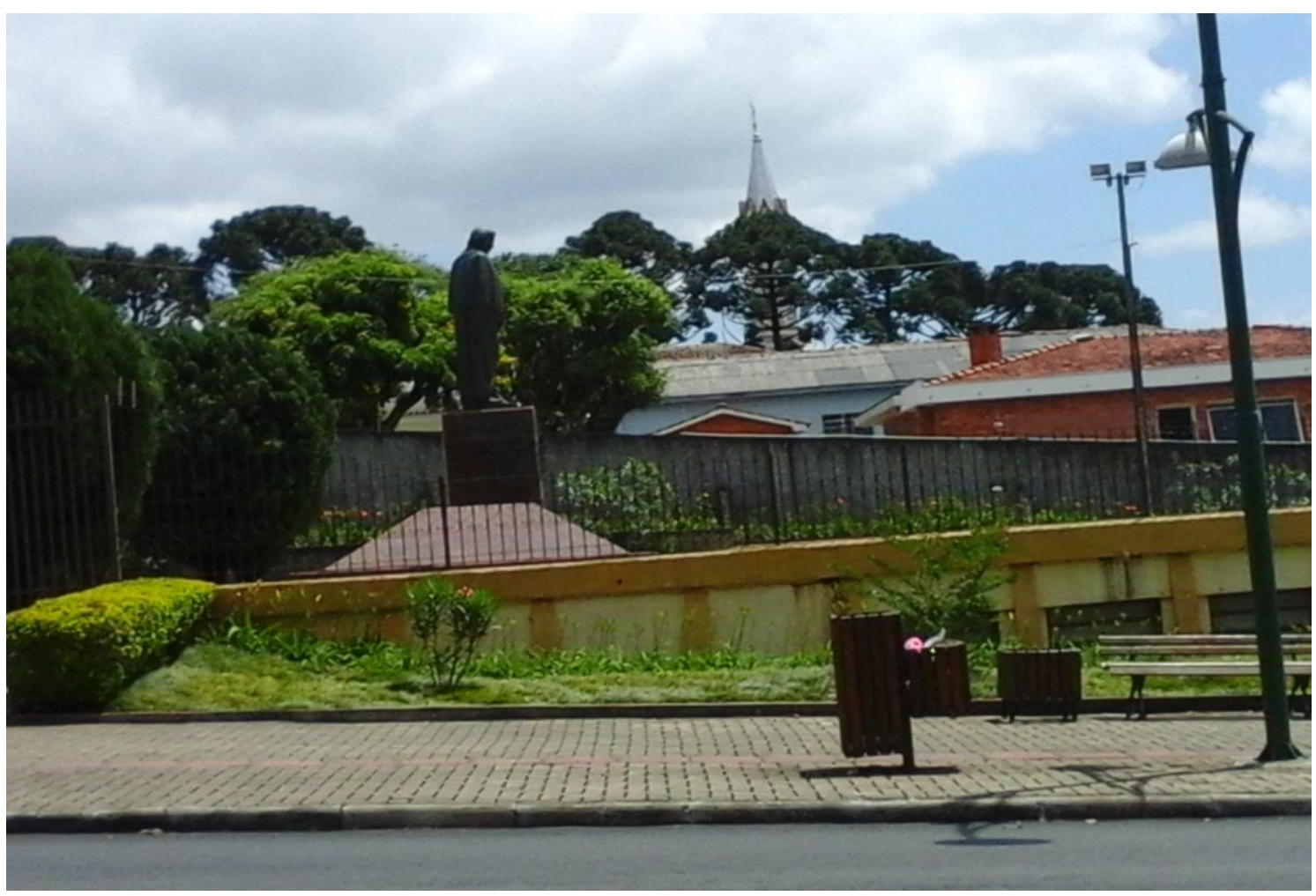

Fonte: Mageroski (2017).

A paisagem possui a virtualidade de reter a ideia do passado. Quando concebida como paisagem cultural, passa a considerar não somente os objetos construídos como o foco da preservação, mas todo o seu contexto de inserção, amalgamando as ações, os processos e o produto do trabalho, o patrimônio cultural e o ambiental.

Por mais que o Jornal Prácia tenha sua origem muito ligada à igreja Católica, foi possível, através das leituras das edições, extrair inúmeras informações relativas à paisagem que não estavam ligadas à questão religiosa. Esses elementos permitiram notar a valorização das atitudes sociais na confecção do ambiente, no perpassar dos processos históricos (PIMENTA, 2015).

Assim, outro elemento material descrito nas edições do Jornal e que marca significativamente a paisagem de Prudentópolis é constituído pelas construções residenciais típicas da cultura ucraniana. No Prácia, 
encontramos descritas detalhadamente como eram as marcas na arquitetura: a pintura em tons fortes (Figura 4), e os detalhes dos lambrequins das varandas e suas cercas (Figura 5).

Sobre esse aspecto da paisagem, o Jornal Prácia noticiou: “[...] o povo ucraniano sempre foi prestigiado pela limpeza das casas, bem como pela deslumbrante organização. Como diz o ditado: é preciso ter bom paladar e uma graciosa organização [...]” (PRÁCIA, 1964, n 2282, p. 6); “[...] repassamos algumas dicas para a ornamentação das paredes das casas: "quadros de Deus, Cristo, Maria, bem como dos Santos devem ser de tamanhos grandes, retos e pendurados acima dos demais quadros, fotos e terceiros [...]” PRÁCIA, 1964, n 2282, p. 6); “[...] as donas de casa cuidem de suas casas, para que se torne agradável entrar nelas [...]" (PRÁCIA, 1964, nº 2282, p. 6).

De acordo com Nór (2013), a identidade do lugar pode estar vinculada ao sujeito, suas memórias, suas interpretações, suas ideias e seus afetos, e pode, também, emanar do próprio lugar, manifestada em seu espírito. O espírito do lugar, ou genius loci, está ligado às relações entre os componentes materiais e imateriais presentes em determinado espaço, seja ele natural ou construído. Ele revela, por meio das permanências, o diálogo entre passado e presente, conferindo um caráter vivo e permanente às paisagens (NÓR, 2013).

Por meio das relatos expressos em forma de notícias do Jornal Prácia, encontramos especificidades dos traçados urbanos, como sua rua comercial, as localizações típicas das igrejas em elevações ligeiramente apartadas dos eixos principais, seus bairros originados pela absorção das antigas linhas coloniais rurais e das pequenas propriedades, então, desmembradas. 
Figura 4 - Casa típica ucraniana em Prudentópolis, 2017

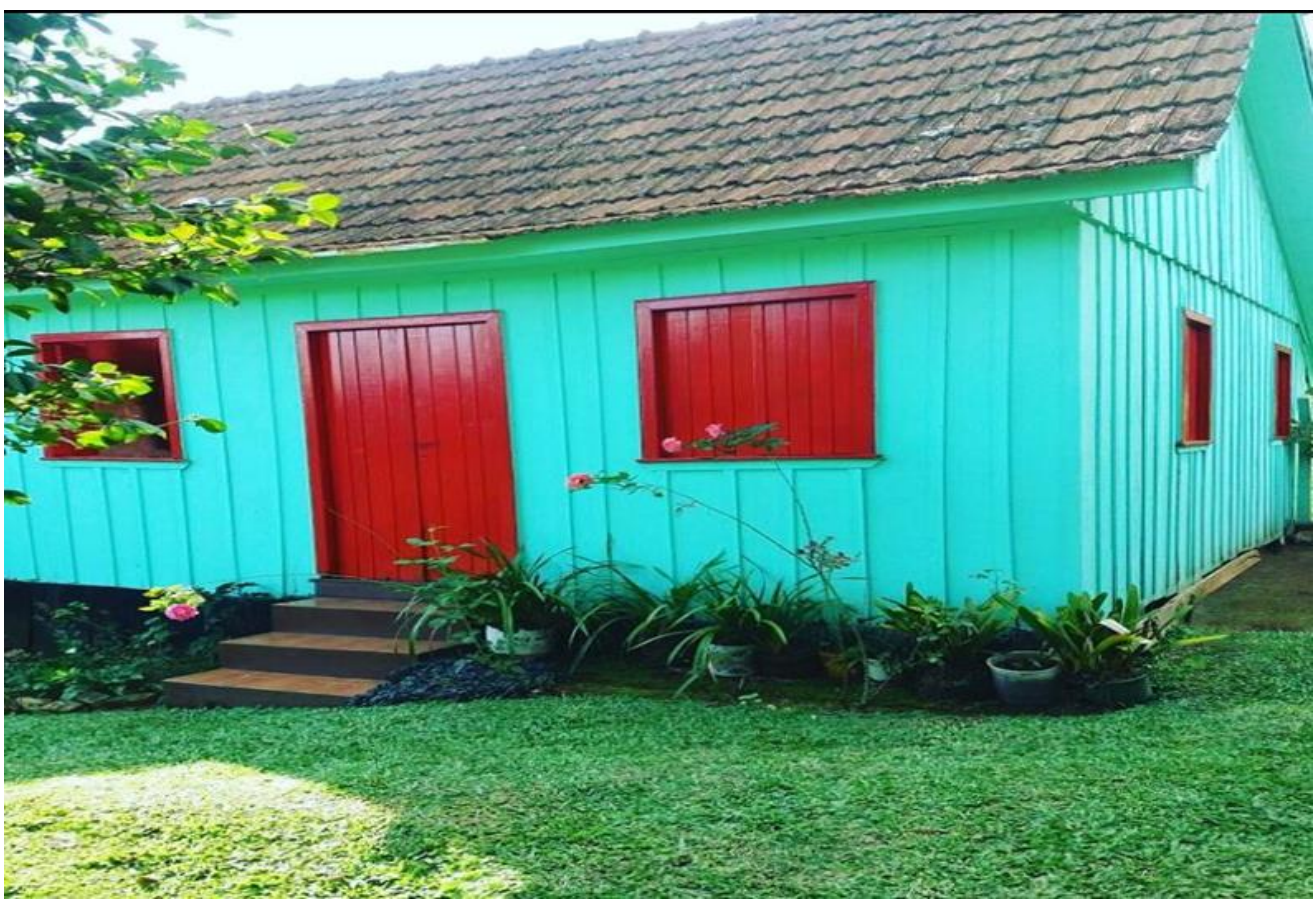

Fonte: Mageroski (2017).

Figura 5 - Casa típica ucraniana em Prudentópolis, 2017

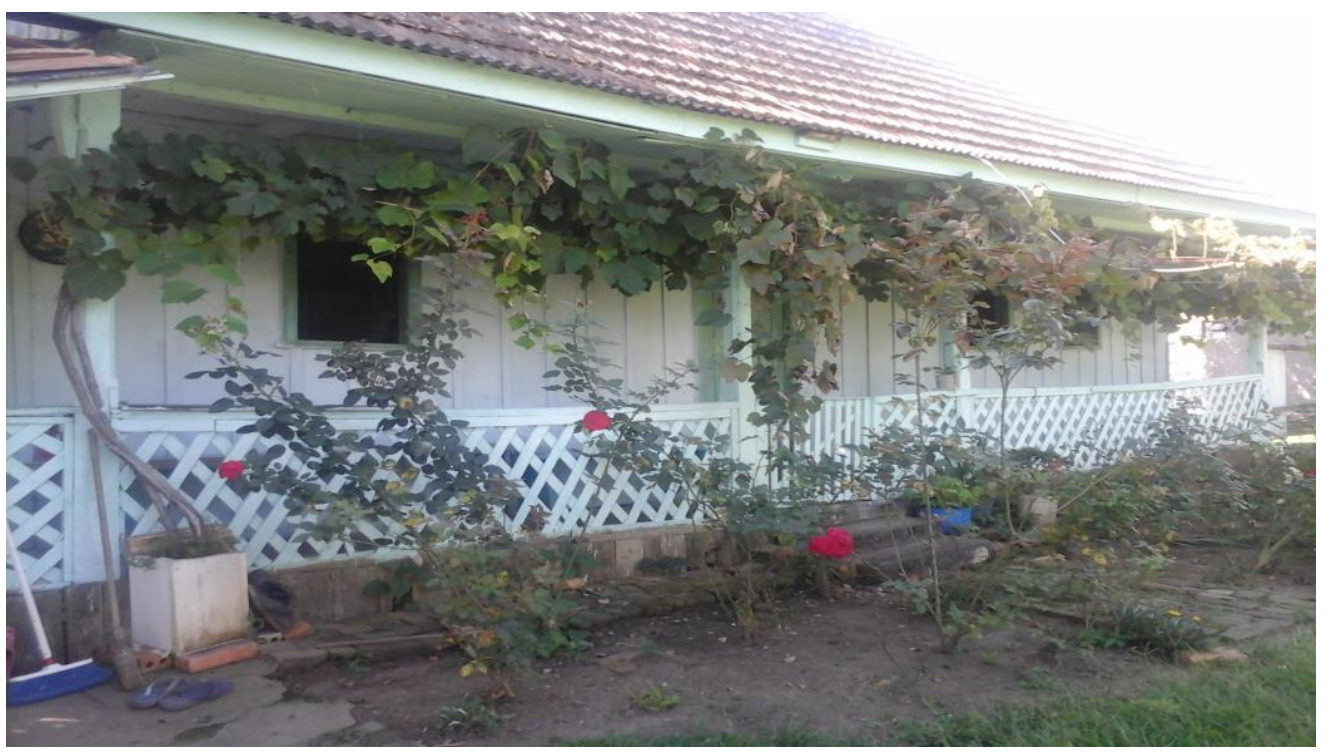

Fonte: Mageroski (2017).

Se os exemplos arquitetônicos ao longo da história têm criado um cenário que distingue Prudentópolis de outras cidades brasileiras, concordamos com Augé (1994), quando afirma que o lugar é o espaço onde se 
expressam e se afirmam os valores sociais e culturais de uma população, e onde se materializa a sua identidade simbólica. Em Prudentópolis, o elemento constitutivo dos grupos sociais permite que seus habitantes se reconheçam e se definam nele, desempenhando importante papel na estrutura identitária dos indivíduos.

A arquitetura das edificações marca a história de cidades, como é o caso dos traços da cultura ucraniana presentes na identidade cultural da população de Prudentópolis, e isto pode ser definido como a espacialização das relações sociais.

\section{Considerações Finais}

Inquestionavelmente os povos eslavos que imigraram para o Brasil contribuíram para a diversificação e o enriquecimento da cultura do país. Tal perspectiva implica a investigação e o reconhecimento dos aportes culturais desses imigrantes e seus descendentes em termos da realidade brasileira.

Eles estabeleceram e estabelecem relações múltiplas e mutáveis, ainda pouco estudadas ou, talvez, insuficientemente compreendidas, com a natureza, com as populações nativas, com os usos e costumes e com o mundo ao seu entorno. Há muito o que se estudar sobre o tema, especialmente no que se refere à arquitetura, à alimentação, à construção de identidades, à religiosidade, ao folclore, aos rituais e artes.

Neste sentido, pensar a cultura é considerá-la um fenômeno em constante mutação, implicando a necessidade do registro dos aspectos tidos como importantes para o seu próprio reconhecimento e a compreensão dos sujeitos que entram em contato com ela. Em nossa pesquisa buscamos, nos registros do Jornal Prácia, encontrar como a diversidade cultural dos imigrantes ucranianos expressa na paisagem da cidade de Prudentópolis tornou possível que esse grupo se reconhecesse como tal em terras 
brasileiras. Ao longo dos anos, vem sendo um instrumento de registros de como os imigrantes conseguiram resistir e mantiveram toda uma tradição ainda de forte presença na sociedade paranaense.

Os registros mapeados no Jornal, mesmo que não intencionlamente, foram responsáveis, em muitos momentos da história, pela propagação e difusão da cultura dos imigrantes ucranianos, quando retrataram, por exemplo, a opressão no país de origem, e mesmo no Brasil, ao sofreram discriminações por praticarem seus usos e costumes, em especial, o idioma. A discriminação e o preconceito linguístico levaram muitos a abandonar o idioma, os rituais, os costumes herdados dos antepassados.

Assim, considerando os imigrantes ucranianos e o estudo da paisagem pelo viés cultural, destacamos seus códigos culturais e a identidade do grupo. Dentre as facetas políticas, sociais e religiosas em muitas outras publicações do Prácia, ele também vem sendo o principal veículo para a compreensão da imigração, norteando a representatividade desse grupo.

A paisagem é dinâmica e seus elementos transformam-se pela ação das forças naturais e culturais em suas dimensões material e imaterial, por meio da marca da cultura dos povos sobre o território que ocuparam.

Em consonância com a lógica cultural contemporânea, a construção de identidades, valorização das diferenças, ecletismo, estetização e tradição são experiências que, de certa maneira, criam um novo modo simbólico de afiliação e pertença a um território. Isto através do esforço que reformulou o sentido de signos que pudemos encontrar expressos em várias edições do Jornal Prácia que utilizamos nesta pesquisa.

Nesta dinâmica, na forma como vem se configurando a paisagem de Prudentópolis, há mais de um século, sobretudo a partir da chegada dos imigrantes ucranianos, há um forte elemento interseccional entre antigo e novo, a tradição e as novas culturas, o histórico e o moderno que se fundem no mesmo espaço. Estas consonâncias são evidentes quando analisamos os elementos que foram sendo constitutivos da paisagem da cidade e são 
registrados no Jornal, mesmo que, naquele momento histórico, eles nada representassem.

A partir da compreensão de que a paisagem é dinâmica e constantemente submetida a transformações, dependendo como a mudança ocorre, seus elementos culturais e naturais podem ser ameaçados. Trazer à tona o que foi registardo no Jornal Prácia ao longo de mais de um século de existência permite comparar as interações do ontem com o hoje. A junção de uma análise documental com a análise do presente pemite o reconhecimento da paisagem como detentora de valor patrimonial e de identidade.

Entendemos que a concepção de paisagem está relacionada à interpretação do sujeito que a visualiza e a vivencia. Assim, trazer à vista os elementos expressos na paisagem, mesmo que de forma não intencional pelo Jornal a cada momento em que uma edição era finalizada, possibilitou identificarmos como vêm ocorrendo as transformações socioespaciais em Prudentópolis e os seus efeitos na paisagem.

\section{Referências}

ANDREAZZA, M. L. O paraíso das delícias: estudo de um grupo imigrante ucraniano. 1895-1995. Curitiba, 1996. Tese (Doutorado em História). Setor de Ciências Humanas, Letras e Artes, Universidade Federal do Paraná.

AUGÉ, M. Não-lugares: Introdução a uma antropologia da supermodernidade. Campinas, SP : Papirus, 1994.

BALHANA, A. P. Política imigratória do Paraná. Rev.Paraná Desenvolv., Curitiba, n.87, jan/abr., p. 39-50.

BERQUE, A. Paisagem-marca, paisagem-matriz: elementos da problemática para uma geografia cultural. In: CORREA, R. L.; ROSENDAHL Z. (Org). Paisagem, tempo e cultura. $2^{\text {a }}$ edição. Rio de Janeiro: EdUERJ, 1998, p. 84-91.

BORUSZENKO, O. Os ucranianos. Boletim Informativo da Casa Romário Martins, v.2, 1995.

BURKO, V. A imigração ucraniana no Brasil. Curitiba - PR, 1963.

BRASIL; Lei $\mathrm{n}^{\circ}$ 10.406, de 10 de Janeiro de 2002. Dispõe sobre todos os documentos redigidos em língua estrangeira serão traduzidos para o português para ter efeitos legais no país.

BRASIL, Lei $\mathrm{n}^{0} 1.545$, de 25 de agosto de 1939. Dispõe sobre a previa a adaptação do imigrante ao território brasileiro, proibia à língua, e a publicação de revistas, jornais, folhetos em língua estrangeira. 
CABRAL, L. O. Revisitando as noções de espaço, lugar, paisagem e território, sob uma perspectiva geográfica. Revista de Ciências Humanas, v.41, n.1 e 2, p. 141-155,2007. Disponível em: https://periodicos.ufsc.br/index.php/revistacfh/article/viewFile/15626/14158 CAETANO, J. N.; BEZZI, M. L. Reflexões na Geografia cultural: a materialidade e a imaterialidade da cultura. Sociedade \& Natureza, v.23, n.3, 2011. https://doi.org/10.1590/S1982-45132011000300007

CORRÊA, R. L.; ROSENDAHL, Z. Paisagem. Tempo e Cultura. Rio de Janeiro, 1998.

CORRÊA, R. L.. Formas simbólicas e espaço: algumas considerações. Aurora Geography Journal, v.1, p. 11-19, 2007.

CORRÊA, R. L. A dimensão cultural do espaço: alguns temas. Espaço e Cultura. Rio de Janeiro, v.1, n.1, p. 1-22, out de 1995.

COSGROVE, D. John Ruskin and the geographical imagination.Geographical Review, v.69, n.1, 1979, p. 43-62.

COSGROVE, D. Em direção a uma geografia cultural radical: problemas da teoria. In: Introdução à Geografia Cultural. CORRÊA, R.L.; ROSENDAHL, Z. (orgs.). Rio de Janeiro: Bertrand Brasil, 2003 (1983).

COSGROVE, D. The Palladian Landscape: Geographical Change and its Cultural Meanings in Sixteenth Century Italy. Londres: Leicester University Press, 1993.

COSGROVE, D. Social formation and symbolic landscape. Madison: the University of Winsconsin Press, 1995.

COSGROVE, D. A Geografia está em toda parte: cultura e simbolismo nas paisagens humanas. In: CORREA, R. L.; ROSENDAHL, Z. Paisagem, Tempo e Cultura. Rio de Janeiro: EdUERJ, 1998, p. 100.

COSTA, O. Memória e Paisagem: em busca do simbólico dos lugares. Espaço e Cultura, Rio de Janeiro, Ed. Comemorativa 1993-2008, p. 149-156, 2008.

DARDEL, E. O homem e a Terra: natureza da realidadegeográfica. São Paulo: ed. Perspectiva, 2011.

DARDEL, E. L'homme et la terre - nature de la réalité geographyque. Paris: CTHS, 1990.

ESCUDERO, C. Imprensa de comunidades imigrantes de São Paulo e identidade: estudo dos jornais ibéricos Mundo Lusíada e Alborada. Dissertação (Mestrado em Comunicação Social) - Universidade Metodista de São Paulo: São Bernardo do Campo, 2007.

FROEHLICH, J. A (re) construção de identidades e tradições: o rural como tema e cenário. In: FROEHLICH, J.; DIESEL, V. (orgs). Espaço rural e desenvolvimento regional. Ijuí: EDUNIJUÍ, 2004. 312 p.

GIL, A. C. Técnicas de pesquisa social. São Paulo, Editora Atlas, 2008.

GUÉRIOS, R. F. Memória, identidade e religião entre os imigrantes rutenos e seus descendentes no Paraná. 2007. 292 f. 2007. Tese de Doutorado. Tese (Doutorado em Antropologia Social), Museu Nacional, Universidade federal do Rio de Janeiro.

HIRSCH, E. Introduction: Landscape: between place and space. In: HIRSCH, E. et al. (Eds.), Theanthropology of landscape: perspectives on place and space (1-30). Oxford: Clarendon Press, 1995.

Jornal Prácia, Prudentópolis, no 46, p. 9, 17 de mar. de 1923.

Jornal Prácia, Prudentópolis, no 48, p. 13, 20 de mar. de 1923.

Jornal Prácia, Prudentópolis, no 12, p. 2, 17 de ago. de 1929.

Jornal Prácia, Prudentópolis, no 48, p. 2, 20 de abr. de 1935.

Jornal Prácia, Prudentópolis, no 44, p. 2, 12 de abr. de 1936.

Jornal Prácia, Prudentópolis, no 34, p. 4, 12 de jul. de 1939.

Jornal Prácia, Prudentópolis, n⿳0 2282, p. 6, 15 de set. de 1964 .

Jornal Prácia, Prudentópolis, nº 16, p. 5, 14 de jan.de 1986.

Jornal Prácia, Prudentópolis, nº 18, p. 15, 18 de mar. de 1988.

Jornal Prácia, Prudentópolis, nº 15, p. 8, 28 de jan. 1995.

Jornal Prácia, Prudentópolis, nº 24, p. 9-11, 1 de mar. de 2012. 
LOPEZ, L. R. História do Brasil contemporâneo. 2. ed. Porto Alegre, 1983.

MELO, V. M.; ROSENDAHL, Z.; CORRÊA, R. L. Paisagem e simbolismo. Paisagem, imaginário e espaço, 2001.

NÓR, S. O lugar como imaterialidade da paisagem cultural. Paisagem e Ambiente, n.32, p. 119-127, 2013. https://doi.org/10.11606/issn.2359-5361.v0i32p119-127

PEREIRA, A. J. Leituras de paisagens urbanas: um estudo de Araguaína - TO. Tese (Doutorado em Geografia) - Universidade Federal de Uberlândia em Uberlândia/MG, 2013.

PIMENTA, M. de C. A. A paisagem cultural: multiplicidade interpretativa e políticas de preservação. Ateliê Geográfico. Goiânia-GO, v.10, n.2, p. 97-114, agosto/2016. https://doi.org/10.5216/ag.v10i2.38054

SANTOS, M. Metamorfoses do espaço habitado. São Paulo: Hucitec, 1988.

SANTOS, M. A natureza do espaço: técnica e tempo, razão e emoção. Edusp, 2002.

SAQUET, M. A. Abordagens e concepções de território. São Paulo: Expressão Popular, 2007.

SCHIER, R. A. Trajetórias do conceito de paisagem na Geografia. Revista RA'E GA, Curitiba, n.7, p. 79-85, 2003. https://doi.org/10.5380/raega.v7i0.3353

VENDRUSCOLO, R. Somos da Quarta Colônia: Os sentimentos de uma identidade territorial em construção. 2009. 210f. Dissertação (Mestrado em Extensão Rural)Universidade Federal de Santa Maria, Santa Maria, 2009. 